\title{
PENGARUH GAYA KEPEMIMPINAN, DISIPLIN KERJA DAN KEPUASAN KERJA TERHADAP KINERJA KARYAWAN
}

\author{
Shella Oktavia ${ }^{1}$, Yanuar $^{2}$ \\ ${ }^{1}$ Program Studi Manajemen, Fakultas Ekonomi dan Bisnis, Universitas Tarumanagara \\ Email: shella.115170249@stu.untar.ac.id \\ ${ }^{2}$ Program Studi Manajemen, Fakultas Ekonomi dan Bisnis, Universitas Tarumanagara* \\ Email: yanuar@fe.untar.ac.id \\ *Penulis Korespondensi
}

Masuk : 02-08-2021, revisi: 15-08-2021, diterima untuk diterbitkan : 30-08-2021

\begin{abstract}
ABSTRAK
Tujuan penelitian ini adalah untuk mengetahui dan menganalisa pengaruh gaya kepemimpinan, disiplin kerja dan kepuasan kerja terhadap kinerja karyawan PT XYZ. Penelitian ini dilakukan dengan metode probability sampling dengan teknik purposive sampling. Peneliti mendistribusikan kuesioner ke 100 pimpinan dan karyawan di PT XYZ. Analisis data dilakukan dengan analisis PLS-SEM. Hasil pengujian hipotesis menunjukkan bahwa gaya kepemimpinan, disiplin kerja, dan kepuasan kerja memiliki pengaruh yang positif dan signifikan terhadap kinerja karyawan.
\end{abstract}

Kata Kunci: Gaya kepemimpinan, disiplin kerja, kepuasan kerja, kinerja karyawan

\section{ABSTRACT}

The purpose of this study is to find out and analyze the influence of leadership style, job discipline and job satisfaction on employee performance at PT XYZ. This research was conducted by probability sampling method with a type of purposive sampling. The researcher distributed questionnaires to 100 leaders and their sub-ordinates at PT XYZ. Data analysis using PLS-SEM analysis. The results of hypothesis testing prove that leadership style, job discipline and job satisfaction have positive and significant value on employee performace.

Keywords: Leadership style, work discipline, job satisfaction, employee performance

\section{PENDAHULUAN}

\section{Latar Belakang}

Sumber Daya Manusia (SDM) memiliki peran krusial bagi sebuah organisasi. Jika sebuah organisasi hendak mencapai sebuah tujuan atau pun visi, maka peran sumber daya manusia sangat dibutuhkan untuk mencapai tujuan tersebut. Menurut Dessler (2016) manajemen sumber daya manusia (MSDM) adalah proses memperoleh, melatih, menilai, dan memberi kompensasi kepada karyawan, dan memperhatikan hubungan kerja mereka, kesehatan dan keselamatan, dan masalah keadilan. Berdasarkan pernyataan diatas, maka sangat penting bagi perusahaan khususnya Manajemen Sumber Daya Manusia (MSDM) untuk mengelola Sumber Daya Manusia (SDM) dengan baik sehingga karyawan dapat memberikan hasil yang sejalan sesuai dengan kebutuhan visi serta misi dari perusahaan. Namun pada kenyataannya pengelolaan karyawan menjadi kendala yang harus diperhatikan perusahaan terutama kinerja karyawan.

Ada beberapa pengaturan dalam MSDM dan salah satu diantaranya adalah tentang kedisiplinan karyawan. Menurut Dessler (2016) disiplin adalah prosedur yang mengoreksi atau menghukum bawahan karena aturan atau prosedur telah dilanggar. Kinerja karyawan merupakan suatu hal yang sangat penting dalam suatu perusahaan untuk mencapai target operasionalnya. Dessler 
(2016) berpendapat bahwa kinerja karyawan adalah prestasi sebenarnya karyawan dibandingkan dengan prestasi yang diharapkan dari karyawan. Prestasi kerja yang diharapkan adalah prestasi standar yang disusun sebagai acuan sehingga dapat melihat kinerja karyawan sesuai dengan posisinya dibandingkan dengan standar yang dibuat. Selain itu dapat juga dilihat kinerja dari karyawan tersebut terhadap karyawan lainnya. Kinerja karyawan mempunyai beberapa faktor yang dapat mempengaruhinya, salah satu faktor yang mempengaruhi kinerja karyawan adalah gaya kepemimpinan. Kinerja adalah fungsi dari kemampuan interaksi, motivasi, dan kesempatan untuk tampil (Yanuar, 2017).

Dalam studi yang dilakukan oleh Obasan \& Hassan (2014) tentang gaya kepemimpinan, kepuasan kerja, dan kinerja memperoleh hasil bahwa gaya kepemimpinan dan kepuasan kerja memiliki hubungan yang positif dengan kinerja karyawan. Sedangkan studi yang dilakukan oleh Lor \& Hassan (2017) memperoleh hasil bahwa beberapa gaya kepemimpinan tidak berpengaruh secara signifikan terhadap kinerja karyawan. Penelitian yang dilakukan oleh Nath \& Agrawal (2015) memperoleh hasil ketidak munculannya korelasi antara kepuasan kerja dengan komitmen organisasi dan kinerja karyawan. Penelitian yang dilakukan oleh Juma \& Moronge (2015) tentang disiplin kerja dan kinerja karyawan di Mukurwe-Ini Wakulima Dairy Ltd memperoleh hasil bahwa disiplin kerja memberi pengaruh yang signifikan terhadap kinerja karyawan. Sedangkan penelitian yang dilakukan oleh Kelimeda et al, (2018) memperoleh hasil hubungan yang tidak signifikan antara disiplin kerja dan kinerja karyawan.

Tujuan utama dari penelitian ini adalah untuk melakukan verifikasi hasil penelitian sebelumnya yang tidak konsisten yaitu pengaruh dan keterkaitan gaya kepemimpinan, disiplin kerja dan kepuasan kerja yang akan mempengaruhi kinerja karyawan. Dalam studi ini peneliti mengambil kasus di PT XYZ merupakan salah satu perusahaan asuransi terkemuka di Indonesia yang menyediakan berbagai produk dan layanan yang dirancang untuk memenuhi dan melengkapi semua kebutuhan keuangan nasabah-nasabahnya di Indonesia. Berikut ini menunjukkan presentase penilaian kinerja karyawan PT XYZ.

\section{Leadership Style}

Menurut Robbins \& Judge (2016) gaya kepemimpinan adalah kemampuan untuk mempengaruhi kelompok menuju pencapaian visi atau set tujuan. Menurut Schermerhorn \& Bond (1997) gaya kepemimpinan merupakan cara atau proses untuk memberikan inspirasi kepada orang lain untuk bekerja keras agar dapat menyelesaikan tugas-tugas yang penting. Seorang pemimpin ini harus bisa menjadi panutan bagi bawahan dapat menjalankan apa yang terjadi arahan dari pemimpinnya. Sementara itu Hersey (1992) menyebutkan bahwa gaya kepemimpinan adalah pola tingkah laku yang berupa kata-kata dan tindakan dari seorang pemimpin yang dirasakan oleh orang lain.

\section{Work Discipline}

Menurut Iheanacho et al. (2017) disiplin kerja adalah hal yang perlu diterapkan untuk memastikan bahwa aturan ditaati demi keberhasilan tujuan. Menurut Pacitti (2011) kedisiplinan adalah sikap dan perilaku dan bertindak menurut ketentuan perusahaan yang ada, baik tertulis maupun tidak.

\section{Job Satisfaction}

Kepuasan kerja menurut Robbins \& Judge (2016) diartikan sebagai perasaan positif tentang suatu pekerjaan, yang dihasilkan darievaluasi karakteristiknya. Seseorang dengan tingkat kepuasan kerja yang tinggimemegang perasaan positif tentang pekerjaannya, sementara orang 
dengan level rendah memegang perasaan negatif. Farooqui \& Nagendra (2014) menjabarkan kepuasan kerja adalah seberapa puas seseorang dengan pekerjaannya. Spector (1997) mendefinisikan kepuasan kerja sebagai perasaan seseorang terhadap pekerjaannya.

\section{Employee Performance}

Menurut Aguinis et al. (2013), pengertian dari kinerja karyawan tidak termasuk hasil dari perilaku karyawannya tetapi hanya perilaku itu sendiri. Kinerja adalah tentang perilaku atau apa yang dilakukan karyawan, bukan tentang apa yang dihasilkan karyawan atau hasil pekerjaan mereka. Menurut Yanuar et al. (2019), prestasi kerja menyangkut dirinya dengan hasil tugas yang diselesaikan oleh karyawan.

\section{METODE PENELITIAN}

Subyek penelitian ini adalah karyawan PT XYZ. Kemudian obyek penelitian ini adalah kinerja karyawan PT XYZ. Populasi dari penelitian ini adalah seluruh karyawan PT XYZ. Teknik pemilihan sampel adalah dengan metode non probability sampling yaitu purposive sampling. Sample dalam penelitian ini adalah 100 responden.

Pada penelitian ini peneliti akan menggunakan software SmartPLS dengan teknis analisis data (SEM) yaitu outer model yang terdiri dari validitas dan realibilitas serta inner model pada bagian analisis data. Pada penelitian ini, digunakan bantuan program SmartPLS 3.0. Model spesifikasi PLS dievaluasi dengan menggunakan dua tahap yatu evaluasi outer model mencakup pengujian validitas dan reliabilitas, serta inner model atau disebut juga analisis struktural.

Tabel 1. Operasional Variabel

\begin{tabular}{|c|c|c|c|}
\hline \multicolumn{4}{|c|}{ ber: Dessler (2UUJ), K } \\
\hline No & Variabel & Indikator & Skala \\
\hline 1 & Gaya Kepemimpinan & $\begin{array}{l}\text { 1. Pemahaman atas pekerjaan/ kompetensi } \\
\text { 2. Kuantitas \& Kualitas } \\
\text { 3. Perencanaan } \\
\text { 4. Inisiatif } \\
\text { 5. Komunikasi } \\
\end{array}$ & Interval \\
\hline 2 & Disiplin Kerja & $\begin{array}{l}\text { 1. Disiplin waktu } \\
\text { 2. Disiplin peraturan } \\
\text { 3. Disiplin tanggung jawab }\end{array}$ & Interval \\
\hline 3 & Kepuasan Kerja & $\begin{array}{l}\text { 1. Pekerjaan itu sendiri } \\
\text { 2. Kompensasi } \\
\text { 3. Promosi } \\
\text { 4. Pengawasan } \\
\text { 5. Teman kerja } \\
\text { 6. Keseluruhan } \\
\end{array}$ & Interval \\
\hline 4 & Kinerja karyawan & $\begin{array}{ll}\text { 1. } & \text { Kualitas } \\
\text { 2. } & \text { Kuantitas } \\
\text { 3. } & \text { Ketepatan waktu } \\
\text { 4. } & \text { Efektivitas } \\
\text { 5. } & \text { Kemandirian } \\
\end{array}$ & Interval \\
\hline
\end{tabular}

\section{HASIL DAN PEMBAHASAN}

\section{Uji Validitas}

Uji validitas konstruk dalam penelitian ini merupakan salah satu rangkaian analisis PLS-SEM yang dilakukan. Dalam validitas konvergen, indikator individu dianggap signifikan secara praktis memiliki nilai outer loading > 0.5 (Abdillah \& Hartono, 2015). 
Tabel 2. Hasil Uji Outer Loading

\begin{tabular}{|c|c|c|c|c|}
\hline & $\begin{array}{l}\text { Disiplin Kerja } \\
\text { (DK) }\end{array}$ & $\begin{array}{c}\text { Gaya Kepemimpinan } \\
\text { (GK) }\end{array}$ & $\begin{array}{c}\text { Kepuasan Kerja } \\
\text { (KEP) }\end{array}$ & $\begin{array}{c}\text { Kinerja Karyawan } \\
(\mathrm{KK})\end{array}$ \\
\hline DK1 & 0,909 & & & \\
\hline DK2 & 0,851 & & & \\
\hline DK3 & 0,802 & & & \\
\hline DK4 & 0,739 & & & \\
\hline DK5 & 0,708 & & & \\
\hline GK1 & & 0,780 & & \\
\hline GK2 & & 0,810 & & \\
\hline GK3 & & 0,779 & & \\
\hline GK4 & & 0,741 & & \\
\hline GK5 & & 0,822 & & \\
\hline KEP1 & & & 0,756 & \\
\hline KEP2 & & & 0,687 & \\
\hline KEP3 & & & 0,675 & \\
\hline KEP4 & & & 0,804 & \\
\hline KEP5 & & & 0,759 & \\
\hline KEP6 & & & 0,832 & \\
\hline KK1 & & & & 0,764 \\
\hline KK2 & & & & 0,626 \\
\hline KK3 & & & & 0,763 \\
\hline KK4 & & & & 0,685 \\
\hline KK5 & & & & 0,749 \\
\hline KK6 & & & & 0,699 \\
\hline
\end{tabular}

Pada pengujian validitas konvergen, terlihat bahwa seluruh indikator pada variabel dianggap signifikan secara praktis memiliki nilai outer loading yang lebih besar dari 0.5.

\section{Uji Reliabilitas}

Selanjutnya adalah melakukan uji reliabilitas instrumen penelitian. Uji reliabilitas instrumen penelitian ini akan menggunakan teknik Cronbach Alpha. Menurut Sugiyono (2018) suatu instrumen dinyatakan reliabel bila koefisien reliabilitas minimal 0,6. Jika instrumen alat ukur memiliki nilai Cronbach Alpha < 0,6 maka alat ukur tersebut tidak reliabel. Pada tahap pengujian ini, analisis reliabilitas dilakukan dengan melihat nilai Cronbach alpha. Hasilnya seperti disajikan pada Tabel 3 berikut ini:

Tabel 3. Hasil Uji Reliabilitas

\begin{tabular}{|l|c|}
\hline \multicolumn{1}{|c|}{ Variabel } & Cronbach's Alpha \\
\hline Disiplin Kerja (DK) & 0.862 \\
\hline Gaya Kepemimpinan (GK) & 0.847 \\
\hline Kepuasan Kerja (KEP) & 0.848 \\
\hline Kinerja Karyawan (KK) & 0.809 \\
\hline
\end{tabular}

Hasil uji reliabilitas pada tabel 3 menunjukkan bahwa seluruh nilai koefisien Cronbach alpha pada masing-masing variabel memiliki nilai lebih besar dari 0,6. Maka dapat disimpulkan bahwa instrumen yang digunakan untuk mengukur variabel-variabel pada penelitian ini sudah reliabel atau layak digunakan untuk langkah pengolahan data selanjutnya.

\section{Uji $R$-Square}

Nilai $R$-Square digunakan untuk mengukur tingkat variasi perubahan variabel independent terhadap variabel dependen. Nilai $\mathrm{R}^{2}$ berada di rentang angka 0 sampai 1 . Jika semakin tinggi nilai $\mathrm{R}^{2}$ dan atau semakin mendekati angka 1 , maka semakin baik model yang digunakan. 
Tabel 4. Hasil Uji Koefisien Determinasi $\left(\mathrm{R}^{2}\right)$

\begin{tabular}{|l|c|c|}
\hline & R-Square & R-Square Adjusted \\
\hline Kinerja Karyawan (KK) & 0.697 & 0.688 \\
\hline
\end{tabular}

Dari hasil pengujian koefisien determinasi pada Tabel 4 di atas, dapat diketahui bahwa nilai Rsquare yang dihasilkan untuk variabel Kinerja Karyawan adalah sebesar 0,697 tergolong kategori sedang. Hasil ini dapat diartikan bahwa sebesar 69,7\% dari kinerja karyawan dapat dijelaskan oleh variabel gaya kepemimpinan, disiplin kerja dan kepuasan kerja sedangkan sisanya yaitu sebesar 30,3\% dijelaskan oleh variabel-variabel yang tidak dimasukkan ke dalam penelitian

\section{Uji Effect Size}

Tabel 5. Hasil Uji f ${ }^{2}$

\begin{tabular}{|l|c|c|c|c|}
\hline & $\begin{array}{c}\text { Disiplin } \\
\text { Kerja (DK) }\end{array}$ & $\begin{array}{c}\text { Gaya Kepemimpinan } \\
\text { (GK) }\end{array}$ & $\begin{array}{c}\text { Kepuasan } \\
\text { Kerja (KEP) }\end{array}$ & $\begin{array}{c}\text { Kinerja } \\
\text { Karyawan (KK) }\end{array}$ \\
\hline Disiplin Kerja (DK) & & & & 0.160 \\
\hline Gaya Kepemimpinan (GK) & & & & 0.071 \\
\hline Kepuasan Kerja (KEP) & & & & 0.071 \\
\hline Kinerja Karyawan (KK) & & & & \\
\hline
\end{tabular}

Berdasarkan hasil perhitungan nilai uji $\mathrm{f}^{2}$, maka dapat disimpulkan bahwa variabel Disiplin Kerja memiliki efek model yang sedang yaitu sebesar 0,160. Gaya Kepemimpinan dan kepuasan kerja memiliki efek model yang kecil yaitu sebesar 0,071 .

\section{Uji Goodness of Fit}

Tabel 6. Hasil Uji Goodness of Fit

\begin{tabular}{|l|c|c|}
\hline & Saturated Model & Estimated Model \\
\hline NFI & 0.670 & 0.636 \\
\hline
\end{tabular}

Berdasarkan hasil pengujian tersebut didapatkan nilai NFI pada model adalah sebesar 0,652. nilai ini mendekati 1 sehingga disimpulkan bahwa ketepatan model sudah baik (Ghozali, 2014).

\section{Uji Path Coefficient}

Path coefficient digunakan untuk menunjukan tingkat signifikansi dalam pengujian hipotesis. Pengujian hipotesis digunakan untuk menguji kebenaran dari suatu hipotesis. Menurut Abdillah \& Hartono (2015) ukuran signifikansi dalam mendukung hipotesis dapat dilihat dari t-statistics dan t-table. Jika t-statistics lebih tinggi dibandingkan nilai t-table, berarti hipotesis didukung atau diterima. Nilai t-table yang digunakan adalah > 1,96 pada alpha 5\%.

Tabel 7. Hasil Path Coefficient

\begin{tabular}{|l|c|c|c|c|c|}
\hline & $\begin{array}{c}\text { Original } \\
\text { Sample (O) }\end{array}$ & $\begin{array}{c}\text { Sample Mean } \\
(\mathbf{M})\end{array}$ & $\begin{array}{c}\text { Standard } \\
\text { Deviation } \\
(\text { STDEV) }\end{array}$ & $\begin{array}{c}\text { t-statistics } \\
(\mid \mathbf{O} / \text { STDEV|) }\end{array}$ & $\boldsymbol{p}$-values \\
\hline $\begin{array}{l}\text { Disiplin Kerja (DK) -> Kinerja } \\
\text { Karyawan (KK) }\end{array}$ & 0.388 & 0.387 & 0.132 & 2.949 & 0.003 \\
\hline $\begin{array}{l}\text { Gaya Kepemimpinan (GK) -> } \\
\text { Kinerja Karyawan (KK) }\end{array}$ & 0.274 & 0.284 & 0.121 & 2.265 & 0.024 \\
\hline $\begin{array}{l}\text { Kepuasan Kerja (KEP) -> Kinerja } \\
\text { Karyawan (KK) }\end{array}$ & 0.242 & 0.241 & 0.106 & 2.287 & 0.023 \\
\hline
\end{tabular}

Dari hasil path coefficient yang disajikan pada Tabel 7 di atas, maka dapat diperoleh persamaan dalam penelitian ini yaitu:

$\mathrm{KK}=0.274 \mathrm{GK}+0.388 \mathrm{DK}+0.242 \mathrm{KEP}$ 
Dapat diketahui bahwa nilai path coefficients gaya kepemimpinan terhadap kinerja karyawan menunjukkan arah yang positif atau searah yaitu sebsar 0,274 . Artinya jika gaya kepemimpinan mengalami peningkatan maka kinerja karyawan PT XYZ juga akan mengalami peningkatan

Dapat diketahui bahwa nilai path coefficients disiplin kerja terhadap kinerja karyawan menunjukkan arah yang positif atau searah yaitu sebsar 0,388. Artinya jika disiplin kerja mengalami peningkatan maka kinerja karyawan PT XYZ juga akan mengalami peningkatan

Nilai path coefficients kepuasan kerja terhadap kinerja karyawan menunjukkan arah yang positif atau searah yaitu sebsar 0,242 . Artinya jika kepuasan kerja mengalami peningkatan maka kinerja karyawan PT XYZ juga akan mengalami peningkatan.

\section{Uji Hipotesis}

Uji signifikansi pada penelitian ini digunakan untuk melihat hubungan antara variabel penelitian dengan melihat hasil dari metode bootstrapping bagian $\mathrm{P}$ values. Pengujian hipotesis digunakan untuk menguji kebenaran dari suatu hipotesis. Menurut Abdillah \& Hartono (2015) ukuran signifikansi dalam mendukung hipotesis dapat dilihat dari t-statistics dan t-table. Jika t-statistics lebih tinggi dibandingkan nilai t-table, berarti hipotesis didukung atau diterima. Nilai t-table yang digunakan adalah > 1,96 pada alpha 5\%.

Hasil pengujian signifikansi dengan bootstrapping pada penelitian terlihat pada tabel berikut:

Tabel 8. Hasil Uji Signifikansi

\begin{tabular}{|l|c|c|}
\hline \multicolumn{1}{|c|}{ Hubungan Variabel } & t-statistics & p-values \\
\hline Disiplin Kerja (DK) -> Kinerja Karyawan (KK) & 2.949 & 0.003 \\
\hline Gaya Kepemimpinan (GK) -> Kinerja Karyawan (KK) & 2.265 & 0.024 \\
\hline Kepuasan Kerja (KEP) -> Kinerja Karyawan (KK) & 2.287 & 0.023 \\
\hline
\end{tabular}

Hipotesis pertama dalam penelitian ini adalah:

H1: Gaya Kepemimpinan memiliki pengaruh yang positif terhadap Kinerja Karyawan.

Berdasarkan hasil pada Tabel 8, dapat diketahui bahwa variabel Gaya Kepemimpinan memiliki pengaruh yang positif terhadap pengaruh yang positif terhadap Kinerja Karyawan. Hal ini dibuktikan dengan t-statistics 2,265 > nilai t-tabel 1,96. Kemudian nilai $\mathrm{p}$ values yang dihasilkan adalah sebesar 0,024 lebih kecil dari cut off value yang ditetapkan yaitu sebesar 0,05. Sehingga dapat disimpulkan bahwa $\mathrm{H} 1$ diterima.

Hipotesis kedua dalam penelitian ini adalah:

H2: Disiplin Kerja memiliki pengaruh yang positif terhadap Kinerja Karyawan.

Berdasarkan hasil pada Tabel 8, dapat diketahui bahwa variabel Disiplin Kerja memiliki pengaruh yang positif terhadap pengaruh yang positif terhadap Kinerja Karyawan. Hal ini dibuktikan dengan t-statistics 2,949 > nilai t-tabel 1,96. Kemudian nilai p values yang dihasilkan adalah sebesar 0,003 lebih kecil dari cut off value yang ditetapkan yaitu sebesar 0,05. Sehingga dapat disimpulkan bahwa $\mathrm{H} 2$ diterima.

Hipotesis ketiga dalam penelitian ini adalah:

H3: Kepuasan Kerja memiliki pengaruh yang positif terhadap Kinerja Karyawan.

Berdasarkan hasil pada Tabel 8, dapat diketahui bahwa variabel Kepuasan Kerja memiliki pengaruh yang positif terhadap Kinerja Karyawan. Hal ini dibuktikan dengan t-statistics 2,287 > 
nilai t-tabel 1,96. Kemudian nilai $\mathrm{p}$ values yang dihasilkan adalah sebesar 0,023 lebih kecil dari cut off value yang ditetapkan yaitu sebesar 0,05 . Sehingga dapat disimpulkan bahwa H3 diterima

\section{Diskusi}

Gaya Kepemimpinan memiliki pengaruh yang positif signifikan terhadap Kinerja Karyawan. Setiap peningkatan gaya kepemimpinan yang semakin baik, akan menyebabkan Kinerja Karyawan semakin meningkat. Indikator gaya kepemimpinan yang memperoleh hasil paling rendah adalah tentang ketepatan waktu pemimpin.

Disiplin Kerja memiliki pengaruh yang positif signifikan terhadap Kinerja Karyawan. Setiap peningkatan pada disiplin kerja, akan menyebabkan Kinerja Karyawan juga semakin meningkat. Indikator yang memperoleh hasil paling rendah adalah tentang hasil kerja karyawan yang kurang maksimal.

Kepuasan Kerja memiliki pengaruh yang positif terhadap Kinerja Karyawan. Artinya bahwa kepuasan kerja yang semakin tinggi akan menyebabkan kinerja karyawan PT XYZ(Kingdom Agency) semakin meningkat. Indikator yang memperoleh hasil paling rendah adalah tentang kepuasan kerja karyawan secara menyeluruh.

Dari antara variabel gaya kepemimpinan, disiplin kerja, dan kepuasan kerja diketahui juga bahwa disiplin kerja memberikan pengaruh yang lebih besar terhadap kinerja karyawan dibandingkan gaya kepemimpinan dan kepuasan kerja terlihat dari angka signifikansi yang paling kecil pada variabel disiplin kerja.

\section{KESIMPULAN DAN SARAN}

Berdasarkan penilaian paling rendah pada Gaya kepemimpinan di PT XYZ, maka atasan perlu lebih memberikan teladan bagi bawahan terutama berkaitan dengan ketepatan waktu dalam pekerjaannya. Hal yang kurang baik yang dicontohkan oleh seorang pimpinan bisa ditiru oleh bawahan. Oleh karena itu, pimpinan perlu memberikan contoh kepada bawahan agar lebih tepat waktu dalam setiap pekerjaannya.

Berdasarkan penilaian paling rendah pada disiplin kerja karyawan PT XYZ maka bawahan disarankan agar memberikan hasil pekerjaan yang lebih maksimal, sehingga bisa memberikan kontribusi kinerja karyawan yang lebih maksimal. Berdasarkan penilaian paling rendah pada kepuasan kerja disarankan agar perusahaan perlu melakukan survey lanjutan atas kepuasan karyawan, karena karyawan belum mendapatkan kepuasan secara menyeluruh selama bekerja di PT XYZ.

\section{REFERENSI}

Abdillah, W., \& Hartono, J. (2015). Partial Least Square (PLS). Yogyakarta: Andi.

Aguinis, H., Gottfredson, R. K., \& Joo, H. (2013). Avoiding a "me" versus "we" dilemma: Using performance management to turn teams into a source of competitive advantage. Business Horizons, 56(4), 503-512.

Dessler, G. (2005). Human Resource Management, 15e. Pearson Education India.

Dessler, Gary. (2016). Manajemen Sumber Daya Manusia, Jilid 1 Edisi 10, Alih Bahasa: Paramita Rahay, (2016), Indeks, Jakarta.

Farooqui, M. S., \& Nagendra, A. (2014). The impact of person organization fit on job satisfaction and performance of the employees. Procedia economics and Finance, 11, 122129. 
Ghozali, I. (2014). Structural Equation Modeling: Concepts and Applications with AMOS program 22.0. Semarang: Publisher Agency Diponegoro.

Hersey, P. (1992). The situational leader (4th ed). Escondido, CA: Center for Leadership Studies. Iheanacho, M. U., Edema, A. J., \& Ekpe, E. O. (2017). Perceived discipline, punishment and organizational performance among employees of federal ministries in cross river state. Global Journal of Educational Research, 16(1), 15-20.

Juma, C. A., \& Moronge, M. (2015). Influence of Progressive Discipline of Employee Performance in Kenya: A Case OF Mukurwe-Ini Wakulima Dairy Ltd. Strategic Journals of Business \& Change Management, 2(105), 1549-1594.

Kelimeda, K., Hairudinor, H., Ridwan, M. N. I., \& Dalle, J. (2018). The effect of motivation, job satisfaction and job discipline toward employee performance of PT. Buma Perindahindo At Lng Tangguh Site, Teluk Bintuni Regency, West Papua, Indonesia. European journal of human resource management studies.

Lor, W \& Hassan, Z. (2017). The Influence of Leadership on Employee Performance Among Jewellery Artisans in Malaysia. International Journal of Accounting and Business Management, 5(1), 14-33.

Nath Gangai, K., \& Agrawal, R. (2015). Job satisfaction and organizational commitment: Is it important for employee performance. International journal of management and business research, 5(4), 269-278.

Obasan Kehinde, A., \& Hassan Banjo, A. (2014). A test of the impact of leadership styles on employee performance: A study of department of petroleum resources. International Journal of Management Sciences, 2(3), 149-160.

Pacitti, A. (2011). Efficiency Wages, Unemployment, and Labor Discipline. Journal of Business \& Economics Research (JBER), 9(3).

Robbins, P. Stephen. (2006). Perilaku Organisasi. Edisi Sepuluh. Diterjemahkan oleh: Drs. Benyamin Molan. Erlangga, Jakarta.

Robbins, S. P., \& Judge, T. (2016). Organizational Behavior.

Schermerhorn, J. R., \& Bond, M. H. (1997). Cross-cultural leadership dynamics in collectivism and high power distance settings. Leadership \& Organization Development Journal.

Sugiyono. (2018). Metode Penelitian Manajemen. Bandung: Alfabeta

Yanuar, Y. (2017). Compensation, motivation and performance of employees: Evidence from Indonesia. Journal of Economic \& Management Perspectives, 11(4), 486-492.

Yanuar, Yenny. L., Ronnie, R.M.. (2019) "Job Performance and Government Banks: Evidence from Indonesia" International Journal of Innovation, Creativity and Change. www.ijicc.net Volume 6, Issue 11, 2019. 